\title{
Chinese National Identity under Reconstruction
}

\author{
Gang Lin and Weixu Wu
}

Soon after Mao Zedong declared on the stage of Tiananmen that the Chinese people had stood up, it seemed that the People's Republic of China (PRC) had almost finished the process of nation building, which had been stimulated by one hundred years of national humiliation and periodic foreign invasions; the only exception then was Taiwan, which had been under the control of Chinese Nationalists (Kuomintang, KMT) since 1945. Over the past seven decades, there have been two Chinese societies governed by different political regimes across the Taiwan Strait. From the perspective of the Chinese mainland, people living in Taiwan, or the so-called Taiwanese, are of course part of "the Chinese," including the overwhelming majority of Han Chinese and the tiny percentage of Taiwanese aboriginals, who are regarded as one of the fifty-five minority ethnicities within the Chinese nation.

The growing sense of Taiwanese identity on the island despite peaceful development of cross-Strait relations over the past eight years, however, has highlighted the marginal existence of Chinese national identity (guojia rentong) on the island. As more people on Taiwan nowadays identify themselves as Taiwanese, rather than as Chinese or both, people on the mainland have worked hard to reconstruct the concept of one China through political communication, economic integration, social exchange, and cultural assimilation across the Taiwan Strait. New slogans such as "two shores, one close family" (liangan yijiaqin) and "both sides [of the Strait] realizing the Chinese Dream" (gongyuan zhongguomeng) have been created and added into the existing political phraseology of "a community of cross-Strait shared destiny" (liangan mingyun gongtongti) and "the great rejuvenation of the Chinese nation" (zhonghua minzu de weida fuxing). 
This chapter discusses Beijing's efforts to reconstruct Chinese national identity in relation to Taiwan. Theoretically, Chinese national identity is both indigenous and reconstructive. The ancient concept of the Middle Kingdom has been enriched continuously, thanks to political expansion and cultural assimilation throughout history. From 1949 to 1979, amid political confrontation and military tension, the Chinese people on the mainland were educated to liberate miserable people on Taiwan and bring the island back to its motherland. From 1979 on, Taiwan's developmental experience and increasing cross-Strait civic exchanges have expanded mainlanders' imagination of modernization and increased their understanding of national identity. Past experience suggests that reconstruction of a Chinese national identity that spans the Taiwan Strait is contingent not only on economic modernization and integration, mutual cultural exchange and assimilation, and reinterpretation of contemporary Chinese history and political relations between the two entities prior to China's reunification, but also on improvement of public governance and political engineering on the mainland.

\title{
THE FACTOR OF TAIWAN IN CHINA'S RECONSTRUCTION OF NATIONAL IDENTITY
}

The mainland Chinese government is obviously worried that if most people in Taiwan identify as Taiwanese and prefer independence this could seriously undermine the prospect of unification in the future. Since the return of Hong Kong and Macau to the motherland, Taiwan's final unification with the mainland has become even more important for China's rejuvenation. This does not mean Taiwan is the last lost territory to be recovered by the motherland, thus ending China's century-old national humiliation by foreign powers. Rather, from Beijing's perspective, the issue of territory recovery has been resolved since the end of World War II. As the Chinese leader Hu Jintao once claimed:

\begin{abstract}
Although the mainland and Taiwan have not been reunited since 1949, the circumstances per se do not denote a state of partition of Chinese territory and sovereignty. Rather, it is merely a state of political antagonism that is a legacy-albeit a lingering one-of the Chinese civil war waged in the mid- to late-1940s. Nevertheless, this does not alter the fact that both the mainland and Taiwan belong to one China. For the two sides of the Strait, to return to unity is not a recreation of sovereignty or territory but an end to political antagonism. ${ }^{1}$
\end{abstract}

From this perspective, separatists in Taiwan are similar to those in Tibet and Xinjiang, even though Tibet and Xinjiang are already under the PRC's control and Taiwan is yet to be unified. To maintain national sovereignty and territorial integrity, Beijing has pragmatically combined these three regions together in its agenda of enhancing national identity. In recent years, Chinese academics have proposed 
to reshape their country's national identity in the new era by strengthening of institutions, good governance, and democratic progress. He Donghang and Xie Weimin point out the problem in the process of China's national identity building: the development of civic identity has fallen behind that of ethnic identity. ${ }^{2}$ According to Yao Dali, it is important to speed up political democratization in order to cultivate and consolidate national identity in a multiethnic country like China. For Yao, the ideas of sovereignty and equality among people of different strata are the spirit of the modern nation-state and also the basic principle of democracy. ${ }^{3}$ Jin Taijun and Mi Jing argue that political ideas such as democracy, freedom, and human rights, as well as institutions based on them, are most important to national identity, particularly to a country where individuals have diverse identities and multiple affiliations, a result of globalization. ${ }^{4}$ Lin Shangli agrees that the most fundamental dimension of national identity is identification with state institutions, which have decisive significance for building modern countries. Democracy is the political foundation of national identity in modern society. ${ }^{5}$

In the case of Taiwan, however, political discourse on the mainland has focused more on cultural similarities, ethnic equivalence, and common economic interests of people between the two sides of the Taiwan Strait, and less on so-called institutional identity (zhidu rentong) - accepting the identity of the economic and political system on the other side of the Taiwan Strait. Obviously, this is because the Taiwanese population is predominantly Han Chinese (except for a tiny portion of aboriginals), and Beijing's unification formula of "one country, two systems" excludes the likelihood of institutional convergence of the two sides of the Strait. It is also because, as Jean-Pierre Cabestan says in chapter 4, many people in Taiwan would easily admit that they are politically Taiwanese but culturally Chinese. Assuming that "blood is thinker than water" (xue nong yu shui), the Chinese mainland government proposed people-to-people exchanges with Taiwan as early as 1979 , when the political and symbolically military confrontation with Taiwan was ended by Beijing's unilateral announcement. Since then, rather than voicing a goal of "liberating miserable Taiwanese compatriots" from the despotic rule of the KMT, Beijing appealed to the island for peaceful unification, pinning its hope not only on the Taiwanese people but also on KMT authorities under the leadership of Chiang Ching-kuo. Blood ties, hometown connections, and ethnic attachment were all employed to reconstruct a linkage between the two long-separated societies. The most dramatic example was a July 1982 open letter to Chiang Ching-kuo written by Liao Chengzhi, minister of the United Front of the Chinese Communist Party (CCP) Central Committee. In the letter, Liao appealed to Chiang Chingkuo that "brothers are still brothers even after painful fighting experience between them, and they can easily forget their mutual hatred with a smile when they meet again" (dujin jiebo xiongdi zai, xiangfeng yixiao min enchou). The story behind this sentimental letter was that Liao's father, Liao Zhongkai, had been a senior leader 
of the KMT back in the 1920s, supporting the KMT-CCP United Front to fight against the Northern Warlords government. Following this open letter, some correspondence by mail continued under the table between leaders of the two sides, and former PRC president Yang Shangkun openly proclaimed in 1987 that the Taiwanese authorities should respect the Chinese "overall national interest" (minzu dayi) and have peace talks with Beijing on unification. On the other side of the Strait, Chiang Ching-kuo even considered sending his formal representative to Beijing for a preliminary political dialogue just before he passed away in January 1988. ${ }^{6}$ Although peace talks on China's reunification between the two ruling parties on each side of the Taiwan Strait did not occur in the 1980s, Chiang Ching-kuo did make a decision in November 1987 to allow cross-Strait family reunions for old soldiers who had followed Chiang to Taiwan in the late 1940s. Beijing's open-door policy and peaceful unification appeal to the island, plus Taipei's 1987 decision, have encouraged more people-to-people exchanges between the two sides based on their family ties, hometown connections, and ethnic feelings, as well as for business reasons. From the mainland perspective, in the absence of meaningful political dialogue between the two sides, cultural and economic factors can serve as antidotes against separatist tendencies on the island that have been beyond PRC control since 1949. Both Jiang Zemin's "Eight Points" (1995) and Hu Jintao's "Six Points" (December 2008) have highlighted the functions of Chinese culture and economic cooperation in linking the two sides of the Taiwan Strait, despite the ups and downs of cross-Strait relations over the past three decades.

\section{“TWO SHORES, ONE CLOSE FAMILY”}

To narrow the gap between the two sides on the issue of national identity and to reconstruct an inclusive Chinese identity across the Taiwan Strait, the Chinese leader Xi Jinping most recently promoted the idea that "compatriots from the two shores of the Taiwan Strait are one close family" when he met the honorary chair of the KMT, Lien Chan, on February 18, 2014. According to Xi Jinping, the blood ties between people on the Chinese mainland and in Taiwan would never be severed. This idea is rooted in the two countries' common ancestry, history, and culture. Cross-Strait ties are not relations between neighbors or friends (let alone enemies) but relations between family members. ${ }^{8}$ By using sentimentally appealing phraseology, such as "both sides fulfilling the Chinese Dream," Xi Jinping attempts to convey the similar ideas that both the mainland and Taiwan belong to one China and that both can "strive for China's reunification." He has emphasized that the unification is a common project of people on both sides of the Taiwan Strait and that unification can be achieved only through China's rejuvenation. Thus peaceful unification is contingent upon peaceful development of the two sides, as well as the "great rejuvenation of the Chinese nation." 
While the appeal to a common culture has long been employed by Chinese mainland leaders in dealing with Taiwan, it has been increasingly used since the mainland's economic takeoff and cultural reconstruction in the 1990s. When former Taiwanese leader Lee Teng-hui recognized Chinese culture as the foundation of cross-Strait exchanges in 1995, he was more confident about Taiwan's role in preserving and reconstructing Chinese culture than mainland China's role. Indeed, cultural sinicization (wenhua zhongguo hua) was one of the four preconditions for national unification according to Taipei's guidelines for it in 1991-with the other three preconditions being economic liberalization, political democratization, and social pluralism. Many people in Taiwan, including some supporters of the proindependence Democratic Progressive Party (DPP), have claimed that Chinese culture is better preserved on the island than on the mainland, since Taiwan has been free of the iconoclastic May Fourth movement and the Cultural Revolution on the other side of the Strait. Cultural reconstruction on the mainland, however, has achieved great progress since the 1990s. Some Confucian ethics and manners have been well adapted to the modernizing Chinese society, and cultural industries have developed quickly. A good example is the architecture of the China Art Museum at Shanghai Expo 2010, which mixed a traditional outlook with modern design. Taipei's desinicization activities under the DPP administration only reminded the mainland of the importance of Chinese culture as the spiritual tie between the two sides.

Cultural exchanges have made great progress since the KMT came back to power in 2008, thanks to Ma Ying-jeou's strong affection for traditional Chinese culture and the Chinese nation. The Cross-Strait Cultural Industries Fair started in 2008 and continued in the following years. The fifth CCP-KMT forum convened in Changsha, Hunan, in 2009 and selected culture and education as the main theme, focusing on (1) preserving the continuity of Chinese culture and fostering innovation; (2) promoting cross-Strait cooperation in cultural industries; and (3) expanding cross-Strait exchange and cooperation on education. In the same year, Fujian initiated the first Strait Forum (haixia luntan) and has convened it every year, focusing on civil and cultural exchanges between the two sides. For example, the 2010 Strait Forum hosted a cultural week focused on Mazu (a sea goddess worshipped by ancient people living in southern Fujian and Taiwan); a cultural festival for Zhu Xi, a famous Confucian scholar in the Song dynasty who was born and spent his life in Fujian; and a forum on Hakka culture. All these activities were aimed at highlighting aspects of Chinese culture that have been shared by people on both sides of the Strait. Meanwhile, other cultural activities with Taiwanese participation, including ancestor worship of the Yellow Emperor in Shanxi and Henan Provinces and an arts festival for Chinese calligraphy in Beijing, occurred on the mainland. ${ }^{9}$ Although the two sides of the Taiwan Strait were unable to sign an agreement on cultural exchanges in Ma Ying-jeou's first term as 
expected, cultural exchanges continued in his second term. The topics of cultural exchanges have ranged over education, publishing, libraries, exhibitions, media communications, religions, music, dance, drama, secular customs and arts, and local culture. The year 2012 witnessed the Cross-Strait Intangible Cultural Heritage Month and the Cross-Strait City Arts Festival in Taiwan, as well as Cross-Strait Cultural Friendship Weeks and the Cultural Exhibition on the mainland. To make books published on the mainland readable by Taiwanese youth, they were converted from simplified Chinese into traditional Chinese and reprinted on the island. In the same year, 1,858 young Taiwanese came to the mainland to study, while 951 mainlanders went to Taiwan as full-time students. According to the statistics of the Department of Culture under the PRC State Council, 324 cross-Strait cultural exchange programs were held in 2013, with 10,802 participants from the two sides. The figures for 2014 were 500 programs and 12,593 participants. ${ }^{10}$ As Liu Xiangping observes, cultural identity is one of the basic elements in national identity, followed by ethnic identity (minzhu rentong) and state identity (guojia rentong). In terms of cultural identity, the two sides are more alike than different, but in terms of national identity, the gap between the two sides has widened. ${ }^{11}$

As Lowell Dittmer points out, one of several objects of national identification is the historical legacy, including consensual interpretations of certain problematic phases in a nation's development when the basic issues of national purpose were raised and decisively resolved in some way. ${ }^{12}$ The mainland government understands very well that differing historical memories may affect national identity negatively. As Xi Jinping said to Lien Chan on February 18, 2014, Chinese mainlanders share the painful feelings that Taiwanese people hold on account of political events in the past, and this is a tragedy for the whole Chinese nation. According to $\mathrm{Xi}$, a strong nation can ensure good fortune for all Chinese compatriots, and a weak and chaotic nation simply means disaster for them. ${ }^{13}$ Because common historical memory is an important factor in shaping civic national identity, mainland media and academic discourse have in recent years highlighted how the CCP and the KMT joined forces to fight the Japanese invasion back in the 1930 and 1940s, as recapped in various movies, newspapers, and journals. In particular, Tengchong, a frontier city in southwestern China and a famous battleground between Japanese troops and the KMT military with US aid, has become a popular location for holding academic conferences that involve scholars from Taiwan, including some from the Green (pro-independence) camp. The mainland's intention is clearly to build up common historical memories with Taiwan, even though young Taiwanese without connection to the old KMT regime may feel that historical events in Tengchong are irrelevant to them. For the same reason, the mainland has retold the story of the famous aboriginal Wushe uprising (also referred as the Wushe incident) against Japanese colonial rule during the 1930s to highlight the common fate of the two sides during a miserable period of Chinese 
history. Indeed, Japan's brutal crackdown on the Wushe uprising and its massacre of the inhabitants of Nanjing occurred in the same decade across the Taiwan Strait. The uprising occurred in October 27, 1930, in a place called Wushe, located in Nantou County, and its participants were the inhabitants described as Seediq, who at that time were considered a subgroup of the Atayal tribe but in April 2008 were recognized as the fourteenth tribe of aboriginals in Taiwan. ${ }^{14}$ The trigger for the uprising was colonial officials' mistreatment of the Seediqs. Under the leadership of Mona Rudao, the Seediqs rose up against the Japanese occupiers in an armed rebellion lasting fifty days and killing well over one hundred Japanese before they themselves were slaughtered in retaliation-about one thousand Seediqs died during the uprising. About eighty years later the Taiwanese film director Wei Te-sheng planned to make a film titled Warriors of the Rainbow: Seediq Bale in September 2008 and finished the film three years later. ${ }^{15}$ The film awoke historical memories of the incident, raising differing views of the incident on the two sides of the Taiwan Strait as well as abroad, particularly on the Internet. The mainstream opinion on the mainland, however, was to link this incident to Chinese resistance against Japanese rule or invasion on both sides of the Strait. ${ }^{16}$

As 2015 was the seventieth anniversary of the Chinese victory in the Chinese People's War of Resistance against Japanese Aggression as well as the Second World War, many activities occurred on the mainland in memory of this victory, aimed at enhancing national identity across the Taiwan Strait. On September 2, the eve of Victory Day in China, Chinese president Xi Jinping awarded medals to veterans who fought in the resistance, including representatives for "eight hundred brave soldiers" (babai zhuangshi) of a KMT troop. In his speech, Xi emphasized that both frontline (zhengmian zhanchang) soldiers led by the KMT and rearguard (dihou zhanchang) soldiers led by the CCP contributed to the final victory and that people fighting on different battlefields were all national heroes. ${ }^{17}$ On September 3, a series of commemorative events-including a rally, a military parade, a reception, and an evening gala-were held in Beijing as planned. Thirty country leaders, as well as representatives from nineteen countries and ten organizations, took part in the events. ${ }^{18}$ Some retired soldiers originally from the KMT troops took part in the military parade, and former KMT chair Lien Chan, New Party chair Yu Mu-min, People First Party general secretary Chin Chin-sheng, and some other dignitaries from Taiwan also attended the commemorative events. In his speech on the rally, $\mathrm{Xi}$ said that the Chinese people had fought tenaciously for fourteen years before winning a great victory in their War of Resistance against Japanese Aggression without mentioning specifically who led that war, the KMT or the CCP, though he did mention, in the reception following the parade, that the war had proceeded under the banner of the "United Front of Resistance against Japanese Aggression Initiated by the CCP." ${ }^{19}$ When Xi met Lien Chan and other Taiwanese representatives on September 1, he highlighted the role of the United 
Front established cooperatively by the CCP and the KMT and expressed appreciation for the cooperation between frontline and rearguard soldiers during the war. Further, Xi intentionally included Taiwanese people's struggle against the Japanese occupation over fifty years as an important part of the whole Chinese nation's war of resistance. ${ }^{20}$ Yu Zhengsheng, chair of the Chinese People's Political Consultative Conference, mentioned one day earlier when he met Lien Chan that during the 1930 s and 1940s more than fifty thousand Taiwanese came to the mainland and joined the War of Resistance against Japanese Aggression. ${ }^{21}$ Lien Chan made similar statements during his meetings with $\mathrm{Xi}$ and $\mathrm{Yu}$, respectively.

However, few people in Taiwan, including KMT leaders, endorsed Lien's activities in Beijing. Both Ma Ying-jeou and Hau Pai-tsun, a senior general and the father of former Taipei mayor Hao Lung-pin, criticized Lien for participating in Beijing's commemorative event. For them, the War of Resistance against Japanese Aggression had been conducted under the leadership of the Republic of China (ROC), which deserved the honor. From the KMT's perspective, the war was part of ROC history. From the perspective of the DPP, however, Taiwan had had nothing to do with the War of Resistance. In fact, during the war more Taiwanese had been recruited by Japanese troops, and toward the end of the war native Taiwanese had suffered from US aircraft bombing. ${ }^{22}$ The typical example of such views is Lee Teng-hui, who openly declared himself as a Japanese before 1945 and who claimed that Diaoyu Island belonged to Japan. It is interesting to note that Lee and Lien were running mates in the 1996 presidential elections and were elected president and vice-president. Lee's remarks reflect a certain nostalgia for Japanese colonial rule, particularly in its late period, among some native Taiwanese. Such feelings, through political socialization, were passed on to some youths, who were uneasy about calling that period between 1895 and 1945 the Japanese "occupation" ( $r$ i ju), as the new teaching outline (kegang) endorsed by the Ma administration did. This resulted in anti-kegang demonstrations in August 2015. Retrospectively, the migration of mainlanders to Taiwan after the war ended in 1945 have has created different "ascriptive categories" in national identification in Taiwan, ${ }^{23}$ an important social feature to be taken into account in political construction and reconstruction of historical memories of the War of Resistance against Japanese Aggression on the island. For the mainland, reconstructing a common memory of the war among people on the two sides of the Taiwan Strait is crucial for building national inclusion. Therefore, Beijing has employed historical memories, in addition to cultural similarities and ethnic equivalence, to retrospectively consolidate the ideational framework of "a community of cross-Strait shared destinies."

Another typical example of historical reconstruction has been the raising of a public memorial in December 2014 for both soldiers of the People's Liberation Army (PLA) and Nationalist troops who died in battle with each other on Jinmen Island in October 1949. The PLA troops, numbered at nine thousand or so, attacked 
Jinmen and held the island for three days but were finally defeated by the Nationalist military with troop reinforcements and an advanced air force. The casualties for each side were several thousand. The political purpose of the memorial is to assuage the lingering historical grievances of people on both sides of the Chinese Civil War and to cherish cross-Strait peace from the perspective of "two shores, one close family." As one retired soldier from Shanghai said during the event, he came to Jinmen in memory of his old colleagues who died on the battleground but ended up with a feeling of respect for all who had died there, regardless of which army - the PLA or the KMT-they had belonged to. Interestingly, at the end of the event, all participants made a military salute to PLA and Nationalist soldiers who had died during the anti-Japanese war. ${ }^{24}$ By doing so, they converted the memory of the tragic civil war into another memory, the glorious cause of all Chinese soldiers fighting against the brutal Japanese invasion prior to 1945. Retrospectively, as a military frontier between Taiwan and the mainland in the 1950s, Jinmen served as a symbolic link between the two sides under the "one-China" framework, simply because both the Nationalist regime on the island and the PRC government on the mainland claimed sovereignty over it, suggesting that China's civil war was not yet over. In recent years, however, Jinmen has served as a peace frontier, starting with the three minilinkages (xiao santong) between it and the PRC-administered island of Xiamen during the Chen Shui-bian administration and followed by an increasing number of visits by mainland tourists. The story of kitchen knives made in Jinmen, using artillery shells left over from the history of bombing Jinmen between the late 1950s and 1970s, when more than one million shells were fired on the small island, is well framed by the public media to encourage the peaceful development of cross-Strait relations. Both Jinmen kitchen knives and Jinmen Gaoliang (a strong liquor) are big sellers for mainlanders traveling there. The role of Jinmen in narrowing the gap between the two sides of the Taiwan Strait has been highlighted by an official meeting there in May 2015 between Zhang Zhijun, director of the Beijing-based Taiwan Affairs Office (TAO) of the State Council, and Xia Liyan, chair of the Taipei-based Mainland Affairs Council (MAC). Because Jinmen is much closer to the mainland than to Taiwan, the two parties have agreed to expedite a contract signed by relevant departments in Fujian and Jinmen to supply water to the island. Other cooperative projects between Jinmen and Xiamen have been discussed in recent years, including a proposed bridge and the supplying of an electrical grid that would cross the two islands.

\section{A COMMUNITY FOR TWO SHORES' SHARED FORTUNE}

Economic exchanges and integration are also considered important for forging community between the two sides of the Strait. According to neoliberal or neofunctional assumptions, economic integration will eventually lead to political 
accommodation and even political integration, as the experience of the European Union has suggested. At least, growing functional interdependency, according to Karl Wolfgang Deutsch's concept of a "security community," will make war too mutually costly to be feasible. Business exchanges between the two sides have evolved from an indirect format in the 1980 s to a direct and comprehensive mode nowadays, particularly since 2008. For example, cross-Strait trade increased from $\$ 129$ billion in 2008 to $\$ 188$ billion in 2015 , accounting for about 30 percent of Taiwan's total foreign trade. Taiwanese direct investment on the mainland that has been approved by the island's authorities increased from $\$ 1.9$ billion in 2008 to $\$ 2.8$ billion in 2012 , though it decreased to $\$ 1.5$ billion in 2015 . Tourists from Taiwan to the mainland increased from 4.37 million person-visits in 2008 to 5.5 million in 2015, while tourists from the mainland to Taiwan jumped from less than 0.28 million person-visits to 4.14 million during the same period. ${ }^{25}$ This increasing economic interdependency has created "linkage communities" (liansuo shequn) between the two sides of the Taiwan Strait, as Yung Wei pointed out one decade ago. ${ }^{26}$ During the 2012 elections in Taiwan, a number of big entrepreneurs publicly supported the KMT idea of "one China, differing interpretations," which is close to Beijing's principle that there is only one China and that only one government (the PRC's) can legitimately represent it but significantly different from the DPP's position that the PRC and the ROC should have "state-to-state" relations. On the other hand, most Taiwanese people have arguably not received direct benefits from increasing economic integration. Despite Beijing's "benefit-offering" (rangli) policy in Strait negotiations on economic affairs, including the signing of the Economic Cooperation Framework Agreement and the Cross-Strait Service Trade Agreement, ordinary people in Taiwan have not experienced much economic revival, for the island in general or their daily life, as a result of cross-Strait exchange. Social cleavages in Taiwan between the rich and poor and between upper strata and lower strata have partly contributed to the strong reaction against the progress of cross-Strait economic and social exchanges, as was vividly revealed by students' Sunflower Movement protesting the Cross-Strait Service Trade Agreement in March 2014. In view of social cleavages in Taiwan, Beijing has paid more attention to the voice of Taiwan's grassroots and youth, who have felt frustrated and relatively exploited amid the process of regional economic integration.

To rebuild a shared Chinese national identity across the Taiwan Strait, Beijing's Taiwan policy makers, in the spirit of neofunctionalism, propose to resolve "economic and easier issues first, and political and difficult issues later." The CCPKMT forums on cross-Strait economic and cultural exchanges after 2006 largely focused on the issue of economic cooperation, except for the 2009 forum, which took cross-Strait cultural and educational exchanges and cooperation as the main theme. Beijing's immediate political goal during the Ma administration was to sign a peace agreement with Taipei and reach a common understanding on the nature 
of political relations between the two sides prior to China's reunification. The years 2013 and 2014 witnessed Beijing's increasing efforts to push political dialogue with Taipei on these issues within a "one China” framework. From Beijing's perspective, if the two sides can have political talks within the framework and can appropriately resolve the issue of Taiwan's participation in the international arena, political relations between the two sides will improve and Taiwanese political identification with the mainland will increase. When Xi Jinping met with KMT chair Chu Li-lun in May 2015, he proposed that the two sides of the Taiwan Strait work together to construct a community with a shared destiny. Xi made five suggestions about how to do this. First, the political foundation of peaceful development of cross-Strait relations would be insistence on the 1992 Consensus (the idea that Taiwan and the mainland constitute one China, though the two sides disagree regarding which of them is its legitimate representative) and opposition to Taiwanese independence. Second, the purpose of promoting peaceful development of cross-Strait relations would be to encourage a convergence of interests of the mainland and Taiwan, reach creatively mutual benefits and win-win outcomes, and increase happiness of compatriots on both sides of the Taiwan Strait. Third, fundamentally speaking, cross-Strait exchanges would be people-to-people exchanges, and heart-to-heart exchanges would be the most important. The two sides would need to enhance ethnic identity, cultural identity, and national identity. Fourth, the CCP and KMT as well as both sides of the Taiwan Strait would need to grasp the general situation and have respect for each other. They would need not only to seek convergence while keeping different views but also to work hard to reduce divergence while increasing common views and political mutual trust. Fifth, the great rejuvenation of the Chinese nation would presuppose the cooperation of both sides. Responding to Xi Jinping's call, the PRC's TAO made it clear that Taiwan was welcome to join the infrastructure development of the so-called "One Belt and One Road" (a network of railways, roads, pipelines, and utility grids linking China to West Asia, Central Asia, parts of South Asia, and Europe) and to participate in the Beijinginitiated Asian Infrastructure Investment Bank in an appropriate capacity.

Beijing's efforts to build a cross-Strait community with a shared destiny have been interrupted by political changes in Taiwan. As the Sunflower Movement protests on March 18 and the outcome of Taiwan's local elections in November 2014 suggested, the January 2016 presidential elections led to another power turnover from the prostatus quo KMT back to the proindependence DPP. Because the ruling DPP does not want to accept the 1992 Consensus, the official and semiofficial relations between the two sides have been broken off, and new agreements for economic and cultural exchanges between the Association for Relations across the Taiwan Strait on the mainland and the Straits Exchange Foundation in Taiwan cannot be reached. Just as $\mathrm{Xi}$ Jinping predicted one year earlier, if the foundation of 1992 Consensus was damaged, cross-Strait relations would return to the earlier situation of chaos and instability. ${ }^{27}$ 
This does not mean that Beijing will necessarily employ military means against Taiwan. Reflecting a fundamental change in China's international standing, Beijing's grand strategy of "peaceful development through reform and opening" has led to the mainland's interdependence with the outside world, especially the AsiaPacific region. ${ }^{28}$ The mainland's growing national capacity has increased its leverage to use either hard or soft tactics, making hard tactics harder and soft tactics softer. Without political consensus between Beijing and the new leadership in post-Ma Taiwan, it is possible that small diplomatic allies of Taiwan will switch their diplomatic ties to the mainland. From the mainland perspective, the issue of Taiwan's international participation can be resolved only within the "one-China" framework. As long as Taipei does not attempt to change the status quo of crossStrait relations in general and to increase its diplomatic allies in particular, Beijing does not need to cut off all of Taiwan's external ties during the transitory period prior to China's reunification. While the maintenance of twenty or so diplomatic allies has only symbolic meaning for Taiwan's foreign relations, their reduction would become a hot issue on an island torn by acute confrontation between the two main parties. Should this happen, Taipei might react strongly against Beijing in one way or another, thus bringing previous tensions back to the Taiwan Strait.

In this situation, Beijing is maintaining its strategy of asymmetric engagement with the two main parties in Taiwan, preferring the KMT to the DPP. The main engines for cross-Strait relations, therefore, are city-to-city and people-to-people exchanges, in addition to the present CCP-KMT platform. However, the September 2016 mainland trip of local executives from one city and seven counties that are under the control of the "Blue" camp (parties more amenable to rapprochement or eventual unification with China, such as the KMT), suggests Beijing's reluctance to have city-to-city exchanges with Green (more proindependence parties such as the DPP) mayors and magistrates unless they accept the "one-China" framework. At a lower level, city districts and neighborhoods, towns and townships, and social groups may become important units for exchange and cooperation. By fostering such connections, the mainland government hopes that its beneficial measures of economic exchange with Taiwan will be felt as much by ordinary Taiwanese people, particularly youth, as by big businesspeople. As TAO director Zhang Zhijun remarked in September 19, 2016, Beijing will insist on the 1992 Consensus, oppose Taiwanese independence, promote peaceful development of cross-Strait relations, and encourage common feelings and benefits of people on both sides of the Taiwan Strait. ${ }^{29}$

\section{RESPECTING EACH OTHER'S SOCIAL SYSTEM}

Another issue regarding national political identity is the two sides' different political institutions. Beijing has tried to resolve this structural problem by increasing 
the attractiveness of the unification model to Taiwan. According to the formula of "one country, two systems," Taiwan could maintain its own economic, political, and social systems unchanged after unification. Although a postunification China would remain a unitary state, the executive, legislative, and judicial powers enjoyed by Taiwan would surely strain the institutional boundaries of a unitary government and make the relation between mainland and Taiwanese administrations more like that of a federal authority to a state authority. In Taiwan, unlike Hong Kong, political autonomy is rooted in the legal system, rather than being delegated by the central government in the form of basic laws. After unification, Taiwan would retain the right to exercise some sovereign-related powers while giving up other jurisdictions such as national defense and diplomacy, resulting in a quasi-federal relationship between Beijing and Taipei. ${ }^{30}$

The desirability and feasibility of "one country, two systems" are related to two issues facing a rising China: nation building and institution building. Most Chinese studies of "one country, two systems" have focused on the first issue while marginalizing the second. Will the two different economic, social, and political systems coexist forever? How can they work without any conflicts? Will the two systems reduce institutional gaps between them through long coexistence and mutual learning?

In the long process of China's modernization, the PRC has experienced several stages of institution building. In the first three decades from 1949 to 1978 , the regime believed that the socialist system was vastly superior to the capitalist system and would inevitably replace it. Since reform and opening started in 1979, Beijing has relied more on the uniqueness of Chinese circumstances to justify socialism in general and socialist democracy in particular for the Chinese mainland. According to a white paper, entitled Building Political Democracy in China, that was issued by the Chinese government in 2005, there is no single, absolute, and universally applicable democratic model in the world. ${ }^{31}$ In the revised party charter, eliminating class exploitation and social polarization is no longer considered a basic feature of socialism. Moreover, socialist and communist ideals are regarded as suitable to Chinese circumstances and not the only path for other peoples in the world. Although the party at its Eighteenth National Congress in 2012 called for people to retain their confidence in socialism and its theories and institutions, it still defined socialism as suitable to the Chinese situation, rather than as the universal truth for all human beings. Beijing's "one country, two systems" formula, a product of the reform era, seems to match nicely with its outlook on institutional development in the contemporary world, assuming different social systems can coexist and learn from each other, as Jiang Zemin recognized one decade ago. ${ }^{32}$

Whereas "one country, two systems" has been the standard model chosen by Deng Xiaoping and followed by successive Chinese leaders, Xi Jinping has 
attempted to make it acceptable to Taiwan by repeating that the Taiwanese model of "one country, two systems" is different from the Hong Kong model, which is particularly important in the wake of social protests in Hong Kong against the 2017 electoral formula approved by Beijing. When meeting with Lien Chan in February 2014, Xi expressed his understanding that the Taiwanese people cherish (zhenshi) the social system and living style they have chosen for themselves. While social system here obviously includes both economic and political systems, the word cherish suggested that these systems were good for Taiwan and therefore should be appreciated. According to $\mathrm{Xi}$, the mainland not only respects the social system and living style in Taiwan but also wants to share the developmental opportunities on the mainland with the Taiwanese people. ${ }^{33}$ When Yu Zhengsheng, chair of the Chinese People's Political Consultation Conference, made opening remarks at the Sixth Strait Forum, he reiterated Beijing's respect for the Taiwanese social system and lifestyle and added values and ideas to the list. ${ }^{34}$ TAO director Zhang Zhijun repeated what Xi had told Lien Chan while meeting with Kaohsiung mayor Chen Chu in June 2014. Xi’s September 2014 remarks on "one country, two systems" when he met with several prounification or prointegration delegations from Taiwan could be interpreted from the same perspective.

Many politicians in Taiwan have argued that the lack of collective identity between the two sides of the Taiwan Strait is primarily due to different social systems, a democratized Taiwan as opposed to an undemocratic mainland, and have insisted on the importance of Taiwanese democracy as a defense tactic against unification pressure from the mainland. ${ }^{35}$ According to Lin Xinhua from Taiwan, however, the fact that about one million Taiwanese businesspeople live on the mainland with a social system different from that of Taiwan is quite unusual, suggesting that institutional disparity per se cannot prevent people of the two sides from coming together. ${ }^{36}$ For Li Peng of Xiamen University, institutional differences between the two societies should not become problematic as long as each side can humbly and sincerely consider these differences. ${ }^{37}$

This does not mean that the issue of institutional difference, let alone conflict, can be totally neglected. As mentioned above, institutional identification is one of the important elements in national identity. Since the two sides have different political, economic, and social systems, they need to find more commonalities in their institutions, particular in terms of governance. As a matter of fact, the economic system on the mainland has changed dramatically from a planned economy to a market economy over the past thirty-five years, making theoretic differences between capitalism and socialism in the Chinese context increasingly insignificant and Taiwanese businesspeople on the mainland less and less uncomfortable. With the growth of civil society, social organizations, and human rights on the mainland, the institutional gap between the two sides of the Taiwan Strait has been greatly reduced. As the mainland has striven to enhance state governance 
capacities in recent years, Taiwan's experience in governance and public policies can provide useful guidance. While the spirit of "one country, two systems" suggests that different societies can have their respective institutions, accommodating two systems in one country requires overlapping institutional linkages to some degree. As a first step, Taiwanese neighborhood officials (lizhang) and mainland officials at the equivalent level in Shanghai have paid mutual visits and shared their worksite experience. This practice may help to reduce the institutional gap between the two sides at the local level. City-to-city exchanges have also helped to improve government performance and the quality of municipal services on the mainland through learning experience.

\section{CONCLUSION}

The growing sense of a national identity in Taiwan, both on cultural/ethnical dimensions and on political/civic dimensions, has presented a challenge to the mainland's efforts to reconstruct Chinese national identity in modern times. Most people in Taiwan identify themselves as Taiwanese from a civic and political perspective, and a significant portion, though less than one-quarter, would like Taiwan to be independent sooner or later. The gap between Taiwanese consciousness (Taiwan yishi) and the idea of Taiwanese independence is well perceived by Beijing, which has tried its best to accommodate Taiwanese culture under the big umbrella of Chinese culture. That the overwhelming majority of people in Taiwan also recognize they are part of the Chinese nation seems like a good message for a confident Beijing. However, more people in Taiwan prefer independence to unification, and the majority of them would not accept unification with the mainland even if the latter had democratic institutions as Taiwan does.

Despite Beijing's efforts to lay economic, cultural, social, and political foundations for peaceful development of cross-Strait relations as a step toward its final goal of unification, it has a long way to go. Taiwanese feelings toward economic benefits offered by the mainland are neutralized by social dislocation on the island; similar historical and cultural backgrounds of the two sides were interrupted by Japanese colonial rule and long-existing separate governments thereafter; and periods of political détente have been interrupted by crises. All these obstacles have suggested to the mainland that the reconstruction of a shared Chinese national identity across the Taiwan Strait requires not only economic modernization and integration, mutual cultural exchange and assimilation, and reinterpretation of contemporary Chinese history and political relations between the two entities prior to China's reunification but also improvement of public governance and political engineering on the mainland. In other words, the reconstruction of Chinese national identity is a long-term project involving all people on both sides of the Taiwan Strait. 


\section{NOTES}

1. Hu Jintao, "Let Us Join Hands to Promote the Peaceful Development of Cross-Straits Relations and Strive with a United Resolve for the Great Rejuvenation of the Chinese Nation," speech presented at the Forum Marking the Thirtieth Anniversary of the Issuance of a Message to Compatriots in Taiwan, December 31, 2008, transcript, Taiwan Affairs Office of the State Council, PRC, www.gwytb.gov. $\mathrm{cn} / \mathrm{en} /$ Special/Hu/201103/t20110322_1794707.htm.

2. He Donghang and Xie Weimin, "Zhongguo guojia rentong de licheng yu zhiyue yinsu” [Process of Chinese national identity formation and its constraining factors], Makesi zhuyi yu xianshi, no. 4 (2012): 16 .

3. Yao Dali, "Bianhuazhong de guojia rentong" [National identity in transition], Yuanda, no. 1 (2010): 147 .

4. Jin Taijun and Mi Jing, "Cong lingtu fenzhen kan quanqiuhua Beijingxia guojia rentong chonggou" [Reconstruction of national identity under the background of globalization: From the perspective of territory disputes], Jianghai Xuekan, no. 4 (2013): 113-14.

5. Lin Shangli, "Xiandai guojia rentong jiangou de zhengzhi luoji" [The political logic of identity construction in the modern state]" Zhongguo shehui kexue, no. 8 (2013): 27-28.

6. Wu Yuenong, "Qikai haixia liangan heping jiechu lianxi zhimen: Liao Chengzhi gei Chiang Ching-kuo gongkaixin de muhou gushi" [Open the door of peaceful contact between the two sides of the Taiwan Strait: Stories behind Liao Chengzhi's open letter to Chiang Ching-kuo], Zhongshan Fengyu, no. 3 (2004): 8-12.

7. Xi Jinping, "Gongyuan zhonghua minzu weida fuxing de zhongguo meng" [Work together to realize the Chinese dream of great rejuvenation of the Chinese nation], Xinhua Net, February 18, 2014, http://news.xinhuanet.com/politics/2014-02/19c_119394028.htm.

8. Zhang Nianchi, "Xi Jinping de yijiaqin lunshuo yu dangqian liangan guanxi” [Xi Jinping's 'one family' remarks and current cross-Strait relations], China Review (Hong Kong), no. 8 (August 2014): 18.

9. Peng Fuzhi, "Liangan wenhua jiaoliu zhong de zhonghua wenhua rentong yanjiu" [A study on Chinese cultural identity amid cross-Strait cultural exchanges], in Liangan guanxi: Gongtong liyi yu hexie fazhan [Cross-Strait relations: Common interests and harmonious development], ed. Zhou Zhihuai et al. (Beijing: Jiuzhou Press, 2010), 309.

10. Ministry of Culture of the People's Republic of China, 2013 nian wenhua fazhan tongji gongbao [Statistical bulletin on cultural development in 2013], May 20, 2014, www.mcprc.gov.cn/whzx/ whyw/201405/t20140520_433223.html, and 2014 nian wenhua fazhan tongji gongbao [Statistical bulletin on cultural development in 2014], May 19, 2015, www.cssn.cn/zx/yw/201505/t20150519_1939724. shtml.

11. Liu Xiangping, "Laingan rentong zhi jiben yaosu jiqi dacheng lujing tanxi” [A study on basic elements of cross-Strait identification and approaches to reach the goal], Taiwan yanjiu, no. 1 (2011): 1-6.

12. Lowell Dittmer, "Taiwan as a Factor in China's Quest for National Identity," Journal of Contemporary China 15, no. 49 (November 2006): 675.

13. Xi Jinping, "Gongyuan zhonghua minzu weida fuxing de zhongguo meng."

14. "Sediq Recognized as 14th Tribe," Taipei Times, April 24, 2008, www.taipeitimes.com/News/ taiwan/archives/2008/04/24/2003410107.

15. Roy Berman, "Wushe Then and Now," Mutantfrog Travelogue, September 13, 2008, www.mutantfrog.com/2008/o9/13/wushe-then-and-now/; Bruce Foreman, "Seediq Bale': Taiwan's Biggest Movie Sparks Indigenous Tourism," CNN News, November 23, 2011, http://travel.cnn.com/hong-kong/ visit/seediq-bale-401232.

16. "Taiwan wushe shijian: Seediq beihou de gushi" [Wushe incident in Taiwan: The Story behind the Seediq Bale], November 29, 2012, www.36odoc.com/content/12/1119/15/2068001_248784403.shtml; "Huanyuan zuren yanzhong de wushe shijian" [Recovering the Wushe incident in the eyes of people in 
the tribe], Zhongguo Xinwen Wang, November 5, 2012, www.chinanews.com/tw/2012/11-05/4302994. shtml.

17. Xi Jinping, "Zai banfa zhongguo renmin kangri zhanzheng shengli 70 zhounian jinianzhang yishi shang de jianghua" [Address at the ceremony of issuing medals of commemoration of the seventieth anniversary of the victory of the Chinese People's War of Resistance against Japanese Aggression], Zhongguo gongchandang xinwenwang [Chinese Communist Party News Net], September 2, 2015, http://cpc.people.com.cn/n/2015/0902/c64094-27542514.html.

18. "China to Hold Commemorative Events on September 3," Xinhua Net News, August 26, 2015, http://news.xinhuanet.com/english/video/2015-08/26/c_134555451.htm.

19. See Xi Jinping, "Zai jinian zhongguo renmin kangri zhanzheng ji shiji fan fascist zhanzheng qishi zhounian zhaodaihui shang de jianghua" [Address at a reception commemorating the 70 th anniversary of the victory of the Chinese People's War of Resistance Against Japanese Aggression and the World Anti-Fascist War], Xinhua Daily Telegraph, September 4, 2015, 1-2, 4.

20. "Xi Jinping huijian taiwan gejie renshi" [Xi Jinping meets with representatives of all walks of life in Taiwan], Xinhua Daily Telegraph, September 2, 2015, 1.

21. United Daily, September 1, 2015, A4.

22. Author's interviews, September 2, 2015, Taipei.

23. Dittmer, "Taiwan as a Factor," 675.

24. "Liangan minjian jin shouci gongji Jinmen zhanyi zhenwang jiangshi" [First public memorial of casualties of two fighting troops in Jinmen battle by people of the two sides of the Taiwan Strait], Xiamen Net, December 4, 2014, http://news.xmnn.cn/a/xmxw/201412/t20141204_4230944.htm.

25. Su Chi, "Ma zhengfu shiqi liangan guanxi de gaikuang he zhanwang" [The general situation and prospects of cross-Strait relations during the Ma administration, in Liangan guanxi de jiyu yu tiaozhan [Opportunities and challenges for cross-Strait relations], ed. Su Chi and Tung Chen-yuan (Taipei: Wunan Press, 2013), 8; Mainland Affairs Council (Taiwan), “Trade between Taiwan and Mainland China," www.mac.gov.tw/public/MMO/MAC/275_1.pdf, "Transit Trade between Taiwan and Mainland China," www.mac.gov.tw/public/MMO/MAC/275_2.pdf, “Taiwan Investment in Mainland China," www.mac.gov.tw/public/MMO/MAC/275_7.pdf, "Number of Taiwan Tourists to Mainland China," www.mac.gov.tw/public/MMO/MAC/275_14.pdf, and "Number of Mainland China Tourists to Taiwan," www.mac.gov.tw/public/MMO/MAC/275_15.pdf.

26. Yung Wei, “Toward 'Intra-national Union': Theoretical Models on Cross-Taiwan Strait Interactions," Mainland China Studies 45, no. 5 (September/October 2002): 23.

27. Xi Jinping's speech at meeting with Lien Chan, reported by New Chinese News Agency, February 18,2014 .

28. Jing Huang, "Hu Jintao's Pro-Status Quo Approach in Cross-Strait Relations: Building Up a One-China Framework for Eventual Reunification," in The Changing Dynamics of the Relations among China, Taiwan, and the United States, ed. Cal Clark (Newcastle upon Tyne: Cambridge Scholars, 2011), 149.

29. Zhang Zhijun, "Jiang caiqu cuoshi tuidong yu Taiwan ba xianshi jiaoliu" [Measures will be taken to promote exchanges with eight counties and cities in Taiwan], People's Daily (Overseas edition) September 19, 2016, 3 .

3o. Wang Yingjin, "Guanyu yiguo liangzhi Taiwan moshi de xin gouxiang" [New thinking on the Taiwan model of "one country, two systems"], Taiwan yanjiu jikan, no. 6 (2009): 4.

31. State Council Information Office, PRC, Building of Political Democracy in China, 2005, www. china.org.cn/english/2005/Oct/145718.htm.

32. Jiang Zemin, speech at the Central Party School, May 31, 2002, New Chinese News Agency, www.xinhuanet.com.

33. Xi Jinping, speech at meeting with Lien Chan, reported by New Chinese News Agency, February 18, 2014. 
34. Yu Zhengsheng, Opening remarks at the Sixth Strait Forum, Zhongguo Taiwan wang [China Taiwan Web], June 15, 2014.

35. Zhang Yachung, Liangan tonghe lun [On integrating the two sides of the Taiwan Strait] (Taipei: Shengzhi Cultural Publishing, 200o), 130.

36. Lin Xinhua, Chaoguojia shehuixue: Liangan guanxi zhong de xin Taiwan shehui [Transnational sociology: A new Taiwanese society in cross-Strait relations] (Taipei: Weber Culture International Publishing, 2003), 199.

37. Li Peng, "Liangan yijiaqin linian xia de jiangxinbixin siwei qianxi" [An analysis on the thinking of 'put oneself in somebody else's position' under the idea that compatriots from both sides of the Taiwan Straits are of one family], Taiwan yanjiu jikan, no. 1 (2015): 7. 